\title{
O MECANISMO DE DESENVOLVIMENTO LIMPO: OPORTUNIDADES E DESAFIOS PARA O BRASIL
}

\author{
Geraldo Jose Ferraresi de Araujo ${ }^{1}$
}

Cesar Machado Carvalho

Resumo: O capitalismo advindo com a primeira revolução industrial tem, até a globalização, impactado no meio ambiente em escala planetária, colocando em risco a dinâmica climática. Sendo assim, as Nações Unidas através da CQNUMC, na COP 3, realizada em Kyoto, no Japão, instituíram o mecanismo de flexibilização de emissões de gases efeito estufa, dentre eles o MDL que permite que os países desenvolvidos comprem reduções de emissões de países em desenvolvimento cujas reduções são resultantes de iniciativas implementadas com o objetivo de diminuição de emissão de GEE. Logo, o objetivo deste artigo é discorrer sobre o mercado de créditos de carbono e suas oportunidades e desafios para o Brasil através do MDL. Ante o exposto, a metodologia utilizada foi a pesquisa qualitativa documental indireta, onde a bibliografia foi levantada através da INTERNET entre 01/06/2012 até 10/08/2012 e consulta de revistas listadas na Qualis Capes. Pode-se constatar oportunidade de ganhos econômicos e de mitigação de GEE para o Brasil através de projetos ligados a energia, resíduos sólidos, eficiência energética e florestas. Porém, a expiração da primeira fase do Protocolo, em 2012, a recusa dos EUA em ratifica-lo, o custo, o risco e a complexidade de aprovação de projetos MDL são os principais desafios para a consolidação deste mercado a longo prazo. Portanto, é preciso que a diplomacia brasileira trabalhe articulada com outras nações, nas reuniões das COP's, para um segundo período de compromissos do Protocolo, sua simplificação processual e negociação junto ao governo americano pela ratificação do protocolo de Kyoto.

Palavras Chave: Mecanismo de Desenvolvimento Limpo; Oportunidades e Desafios; Brasil.

\footnotetext{
1 Bacharel em Administração pela Faculdade de Economia, Administração e Contabilidade de Ribeirão Preto da Universidade de São Paulo (Avenida dos Bandeirantes 3900, CEP14040-900 — Ribeirão Preto/SP, Brasil). E mail: geraldoferraresi@gmail.com. Fone: 55163602 - 3916. Fax: $55163633-4411$.

${ }^{2}$ Mestrando em Ciências Políticas pela Universidade Federal de São Carlos, Campus São Carlos (Rodovia Washington Luís, Km 235, CEP: 13565-905 - São Carlos/SP, Brasil) Email:cesarmc27@yahoo.com.br. Fone: (16) 3351-8369
} 


\section{INTRODUÇÃO}

Para Klabin (2000), a partir da revolução industrial, na segunda metade do século XVIII, a demanda por energia, sobretudo por reservas de carvão mineral e petróleo, cresceu de forma sistemática.

A primeira pesquisa sobre o aumento da concentração de dióxido de carbono na atmosfera foi realizada no final do século XIX por Arrhenius (1896), onde publicou um trabalho no qual apontava para uma alteração das condições climáticas da atmosfera, produzida pelo $\mathrm{CO}_{2}$ de origem antrópica.

Dessa época até a contemporânea globalização, atual fase de expansão do capitalismo, a concentração de gases causadores do efeito estufa aumentou consideravelmente na atmosfera, sendo os principais: metano $\left(\mathrm{CH}_{4}\right)$, óxido nitroso $\left(\mathrm{N}_{2} \mathrm{O}\right.$, hidrofluorcarbonos (HFCs) e o dióxido de carbono $\left(\mathrm{CO}_{2}\right)$, como é ratificado na tabela abaixo:

\section{TABELA 1 - CONCENTRAÇÃO GLOBAL DE GASES EFEITO ESTUFA}

\begin{tabular}{|l|c|c|c|}
\hline & $\begin{array}{c}\mathrm{CO}_{2} \\
\text { Gás } \\
\text { Carbônico }\end{array}$ & $\begin{array}{c}\mathrm{CH}_{4} \\
\text { Metano }\end{array}$ & $\begin{array}{c}\mathrm{N}_{2} \mathrm{O} \\
\text { Oxido Nitroso }\end{array}$ \\
\hline Concentração em 1750 & $280 \mathrm{ppm}$ & $700 \mathrm{ppb}$ & $270 \mathrm{ppb}$ \\
\hline Concentração em 1998 & $365 \mathrm{ppm}$ & $1745 \mathrm{ppb}$ & $314 \mathrm{ppb}$ \\
\hline Taxa de Alteração & $1,5 \mathrm{ppm} / \mathrm{ano}$ & $7,0 \mathrm{ppb} / \mathrm{ano}$ & $0,8 \mathrm{ppb} / \mathrm{ano}$ \\
\hline Residência na Atmosfera (anos) & $50-200$ & 12 & 114 \\
\hline Fonte: Painel Intergovernamental de Mudanças Climáticas ${ }^{3}(2001$ apud Rocha, 2003, p.1)
\end{tabular}

Conejero (2006) afirma que dentre as ocorrências previstas pelos cientistas do Painel Intergovernamental de Mudanças Climáticas, em decorrência do aquecimento global, destacam-se: derretimento das calotas polares, aumento do nível dos oceanos, aumento

\footnotetext{
${ }^{3}$ IPCC - INTERGOVERNMENTAL PANEL ON CLIMATE CHANGE. Climate change 2001: The scientific basis. Summary for Policy Makers and Technical Summary of the Working Group I Report. WMO/UNEP. 98 p. 2001
} 
da incidência de doenças transmissíveis por mosquitos e outros vetores (malária, febre amarela e dengue), alteração no regime pluvial, intensificação de fenômenos climáticos extremos (secas, inundações, ciclones e tempestades tropicais), desertificação, perda de áreas agricultáveis, problemas relacionados ao abastecimento de água doce e aumento de fluxos migratórios.

Ainda, segundo Cornejero (2006, apud JUSTI, 2008), os desdobramentos socioeconômicos do aquecimento global, devido a uma perda significativa de capacidade produtiva, são: escassez de alimento, alta de preços, queda na renda, desemprego, aumento da pobreza, aumento das desigualdades sociais, aumento do número de conflitos e da violência em geral.

Para Nishi et al (2005), devido as potenciais consequências ambientais, sociais e econômicas, a preocupação com o clima ganhou importância a partir da década de 1970, Desde então, ocorreram reuniões de ordem internacional lideradas pelas Nações Unidas, em que foram discutidas as possíveis soluções para evitar ou, pelo menos, reduzir os impactos relacionados ao aquecimento global, com destaque para Conferência das Nações Unidas sobre o Meio Ambiente e Desenvolvimento Humano, em Estocolmo, em 1972 e em 1992 no Rio de Janeiro (SCARPINELLA, 2002).

Para Ferraresi de Araujo e Carvalho (2011), os acordos internacionais, decorridos da Rio 92, foram: Convenção do Clima, Agenda 21, Convenção da Biodiversidade e a Declaração do Rio.

Especificamente sobre a Convenção do Clima, também conhecida como UNFCCC (United Nations Framework Convention on Climate Change), estabeleceu-se uma série de conceitos, princípios e obrigações. Seu braço executivo é a Conferência das Partes (COP) que se reúne anualmente para avaliar e definir novos caminhos e para traçar acordos sobre questões importantes relacionadas aos objetivos da Convenção em reduzir suas emissões de gases do efeito estufa.

Foi na $3^{\text {a }}$ Conferência das Partes, realizada na cidade de Kyoto, no Japão, em 1997, que se concretizou, o até então, o mais ambicioso compromisso internacional de gradativa redução do lançamento dos gases causadores do efeito estufa na atmosfera através de responsabilidades distintas e diferenciadas entre as nações desenvolvidas e 
em desenvolvimento. Baseia-se, ainda, segundo Conti (2005) em um pressuposto ético: o princípio da responsabilidade comum, quando se trata da defesa da natureza.

Através do Protocolo de Kyoto, foram elaborados e implementados instrumentos de combate ao aquecimento global, dentre eles o Mecanismo de Desenvolvimento Limpo (MDL), modelo que ainda segundo Conti (2005, p. 72) "propõe aos países industrializados a troca da redução das emissões de gases em seus territórios por investimentos em projetos de energia renovável e de absorção de carbono."

Segundo a BM\&F Bovespa (2012), o mercado mundial de carbono ultrapassou, em 2008, valores superiores a US\$126 bilhões, o dobro do valor negociado em 2007. O valor negociado no ano de 2009 foi de US\$144 bilhões (6\% maior que o valor negociado em 2008).

Para Souza (2003), o Brasil, especificamente, tem assumido posição de destaque na proposição de projetos de MDL. A perspectiva é que Brasil tenha participação de no mínimo 10\% nesse movimento. Além de ser uma atividade rentável para o Brasil, estimulará a preservação do meio ambiente. Porém, a recusa do governo dos Estados Unidos em ratificar o Protocolo de Kyoto, a expiração da primeira fase do mesmo em 2012, a complexidade, custo e os riscos para aprovação de projetos MDL são os maiores desafios para consolidação deste mercado em longo prazo.

Dado o exposto acima, o objetivo deste artigo é discorrer sobre edificação do mercado de créditos de carbono e suas oportunidades e desafios para o Brasil através do Mecanismo de Desenvolvimento Limpo.

\section{METODOLOGIA}

Metodologia é uma palavra derivada de "método", do Latim "methodus", cujo significado é "caminho para a realização de algo". O método para Gil (2006) é o processo para se atingir um determinado fim ou para se chegar ao conhecimento. Metodologia é o campo em que se estudam os melhores métodos praticados em determinada área para a produção do conhecimento. 
Logo, dentro do instrumental metodológico, a abordagem desta pesquisa foi qualitativa, para Assis (2008), é uma pesquisa descritiva cujas informações não são quantificáveis; os dados obtidos são analisados indutivamente; a interpretação dos fenômenos e a atribuição de significados são básicas no processo de pesquisa qualitativa.

Dentro da pesquisa qualitativa, o tipo utilizado foi a documentação indireta, através de levantamento bibliográfico. Segundo Andrade (1998), essas denominações se referem muito mais ao ambiente onde se realizam do que ao tipo ou características da pesquisa. Nesse sentido, a pesquisa bibliográfica é um trabalho de pesquisa de toda bibliografia já publicada em forma de livros, revistas, publicações avulsas e artigos que discutem o tema investigado pelo pesquisador em seu trabalho acadêmico, trata-se, portanto de uma prévia seleção de bibliografias que poderão ser utilizados como referências ou "mapas" na construção do artigo.

Ante o exposto acima, as referências bibliográficas foram levantadas pela INTERNET no período de 01/06/2012 até 10/08/2012, no Sistema integrado de Bibliotecas da Universidade Estadual Paulista, Universidade de São Paulo, e a Universidade Estadual de Campinas. Além disso, foram consultadas revistas listadas na Qualis Capes, nas áreas de Administração, Relações Internacionais e Ciências Políticas Ciências Sociais Aplicadas e Interdisciplinares estrato A2 até B5, com enfoque no Protocolo de Kyoto, Mecanismos de Desenvolvimento Limpo, mercado de credito de carbono e oportunidades e desafios para o Brasil.

\section{CONVENÇÃO QUADRO DAS NAÇÕES UNIDAS SOBRE MUDANÇAS CLIMÁTICAS}

As ameaças ambientais, sociais e econômicas, acerca do aquecimento global, levaram os países à Conferência das Nações Unidas sobre o Meio Ambiente, em 1992, no Rio de Janeiro a assinarem Convenção Quadro das Nações Unidas sobre Mudanças Climáticas Globais - CQNUMC. Esta Convenção foi ratificada pelos 154 países mais União Européia.

O objetivo da CQNUMC: 
[...] é o de alcançar, em conformidade com as disposições pertinentes desta Convenção, a estabilização das concentrações de gases de efeito estufa na atmosfera num nível que impeça uma interferência antrópica perigosa no sistema climático. Esse nível deverá ser alcançado num prazo suficiente que permita aos ecossistemas adaptarem-se naturalmente à mudança do clima, que assegure que a produção de alimentos não seja ameaçada e que permita ao desenvolvimento econômico prosseguir de maneira sustentável. (UNFCCC, 1992)

Para a implantação dos objetivos da CQNUMC, foi criado a Conferência das Partes, que segundo Cemano (2004), inclui as nações que ratificaram a UNFCCC e mais um grupo de observadores convidados (organizações internacionais como UNEP, UNCTAD, WMO, OCDE, IEA e ONG's credenciadas). O objetivo da COP é promover a implementação da UNFCCC, revisar compromissos existentes periodicamente levando em conta os objetivos da convenção.

Para Brasil (2012), entre os princípios da COP, está o de "responsabilidades comuns mais diferenciadas" que afirma que cada país deve reduzir suas emissões de GEE, mas, aqueles responsáveis pela maior parte das emissões no transcorrer da história devem fazer um esforço maior. Como resultado deste princípio, países desenvolvidos devem assumir a liderança no combate às mudanças climáticas e seus efeitos adversos, prestando apoio financeiro e tecnológico às nações subdesenvolvidas e em desenvolvimento.

Além disso, a Convenção estabelece que as partes devem cooperar para promover um sistema econômico internacional favorável capaz de promover desenvolvimento econômico sustentável para todos os países, especialmente nações menos desenvolvidas e em desenvolvimento, para que elas possam lidar com as mudanças climáticas.

Em 21 de março de 1994, a convenção entrou em vigor e atualmente conta com 186 países.

\section{A $3^{\circ}$ CONFERÊNCIA DAS PARTES E O PROTOCOLO DE KYOTO}

Em 1997, foi realizada a terceira Conferência das Partes, a COP 3, na cidade de Kyoto, no Japão, contando com representantes de 159 nações e a participação de cerca de 10.000 pessoas que culminou na adoção do Protocolo de Kyoto, um dos marcos mais importantes desde a criação da CQNUMC no combate ao aquecimento global. 
Para Zilber e Koga (2011), o Protocolo de Kyoto foi um acordo assinado por 84 países e definiu que os países elencados no Anexo $\mathrm{I}^{4}$ reduziriam em pelo menos 5,2\% suas emissões de gases de efeito estufa em relação aos níveis de 1990 até 2012, estabelecendo sanções para os não cumpridores, consequentemente, impedindo, para Yu (2004), o avanço da interferência antrópica que causam as alterações climáticas. A União Européia assumiu o compromisso de reduzir em 8\%; os Estados Unidos assinou em uma redução de 7\%; e o Japão concordou em reduzir 6\%. Alguns países como a Rússia e Ucrânia não assumiriam compromisso de redução e outros como Islândia, Austrália e Noruega ainda teriam permissão para aumentar suas emissões.

Para se cumprir as metas definidas pelo Protocolo de Kyoto dos países com compromisso de redução dos GEE, originaram-se os três mecanismos de flexibilização para cumprimento das metas:

- Implementação Conjunta - IC ou Joint Implementation- JI: os países do anexo I trabalham em conjunto para atingir suas metas. (BRASIL, 2002; YU, 2004).

- Comércio Internacional de Emissões: criação de mecanismos internos pelos paises desenvolvidos, nos quais são celebrados acordos entre o governo e as empresas, visando reduções menores que as metas estabelecidas. (BRASIL, 2002; YU, 2004).

- Mecanismo de Desenvolvimento Limpo - MDL ou "Clean Development Mechanism" - CDM: é o que possui aplicabilidade para o Brasil. Nesse caso, os países desenvolvidos podem comprar reduções de emissões de países em desenvolvimento cujas reduções são resultantes de iniciativas implementadas com o objetivo de diminuição de emissão de $\mathrm{CO}_{2}$ e outros GEE desses países (BRASIL, 2002; YU, 2004).

O Protocolo entrou em vigor no dia 16 de fevereiro de 2005, dois meses após ter sido assinado pela Rússia (17,4\% das emissões), completando o mínimo de 55 países que representam pelo menos $55 \%$ das emissões de gases de efeito estufa, conforme

\footnotetext{
${ }^{4}$ Alemanha, Austrália, Áustria, Bielo-Rússia, Bélgica, Bulgária, Canadá, Croácia, Dinamarca, Eslováquia, Eslovênia, Espanha, EUA, Estônia, Finlândia, França, Grécia, Holanda, Hungria, Irlanda, Islândia, Itália, Japão, Letônia, Liechtenstein, Lituânia, Luxemburgo, Mônaco, Nova Zelândia, Noruega, Polônia, Portugal, Reino-Unido e Irlanda do Norte, República do Norte, República Checa, Romênia, Rússia, Suíça, Turquia e Ucrânia.
} 
dispunha o documento. Novamente para Conti (2005), os Estados Unidos, maiores emissores mundiais (36,1\%), negaram-se em aderir sob o argumento de que isso afetaria sua economia, recusa que, evidentemente, tornou frágil a eficiência do Protocolo. O Brasil aderiu em 23 de julho de 2002 (data da sanção presidencial).

\title{
5. O MECANISMO DE DESENVOLVIMENTO LIMPO
}

A partir do Protocolo de Kyoto, foram estabelecidos mecanismos de flexibilização da emissão de GEE, entre eles o Mecanismo de Desenvolvimento Limpo, previsto no Artigo $12^{\circ}$ do Protocolo de Kyoto.

\begin{abstract}
A proposta do MDL consiste em que cada tonelada de $\mathrm{CO}_{2}$ deixada de ser emitida ou retirada da atmosfera por um país desenvolvimento poderá ser negociada no mercado mundial, criando um novo atrativo para a redução das emissões globais. Os países do ANEXO 1 estabelecerão em seus territórios metas para redução de $\mathrm{CO}_{2}$ junto aos principais emissores. As empresas que não conseguirem (ou não desejarem) reduzir suas emissões poderão comprar Certificados de Emissões Reduzidas (MCTI)
\end{abstract}

Segundo Rocha (2003), o MDL consiste em um mecanismo de mercado pelo qual o desenvolvimento sustentável promove ações atenuantes aos impactos ambientais adversos, também, promove ganhos econômicos e financeiros aos parceiros envolvidos através da comercialização dos créditos de carbono.

Ainda de acordo com Rocha (2003), a proposta do MDL consiste em que cada tonelada de $\mathrm{CO}_{2}$ deixada de ser emitida ou retirada da atmosfera por um país em desenvolvimento poderá ser negociada no mercado mundial criando um novo atrativo para redução das emissões globais.

A grande motivação do MDL baseia-se na diferença de custos de redução de emissões de GEE. Essa diferença no custo marginal é o atrativo para o mercado financeiro, de modo a cumprir o acordo com menores preços.

Para Bem e Tonello (2007), o custo para o sequestro de uma tonelada de carbono nos EUA é de US\$236,00, no Japão US\$ 436,00 e na União Europeia de US\$180,00. A participação dos países que não fazem parte do Anexo I pode cortar $55 \%$ dos custos da mitigação de gases efeito estufa, e isso abre perspectivas econômicas para o Brasil que 
possui custo marginal de US\$10,00. Desta forma propõe-se reduzir as emissões por meio de sistema baseado no mercado de licenças de emissões negociáveis para que as reduções se realizem nos locais que forem mais baratas. Os países desenvolvidos podem usar reduções de emissões certificadas em projetos localizados em países em desenvolvimento para cumprir as metas de redução de gases e como parte de seu compromisso.

Segundo Souza (2001), o mercado verde configura-se como uma medida que visa promover programas de desenvolvimento sustentável. De maneira geral, os projetos de MDL podem ser divididos em duas categorias: (I) "projetos de redução de emissão", associado ao deslocamento de emissões oriundas da queima de combustíveis e/ou captura e queima de metano; e (II) projetos de remoção de $\mathrm{CO}_{2}$ atmosférico, ou, como são usualmente chamados, de "sequestro de carbono", relacionados à captação e estocagem de carbono em ecossistemas florestais.

\section{O MECANISMO DE DESENVOLVIMENTO LIMPO E AS OPORTUNIDADES E DESAFIOS PARA O BRASIL.}

O MDL configura-se em uma grande oportunidade para que o Brasil promova o desenvolvimento sustentável e ao mesmo tempo melhore sua capacidade tecnológica e financeira atraindo recursos para a realização de projetos "limpos" (BRASIL. PRESIDÊNCIA DA REPÚBLICA, 2005).

Segundo Ministério da Ciência e Tecnologia (2006), 1412 projetos encontravam-se em tramite para aprovação no $\mathrm{MDL}$, sendo 421 já registrados pelo Conselho Executivo do MDL nas Nações Unidas e 991 em outras fases do ciclo. O Brasil ocupa o 3ำ lugar em número de projeto com 196 (14\%), sendo que em primeiro lugar encontra-se a Índia com 509 e, em segundo, a China com 214 projetos.

Em termos de reduções de emissões projetadas, o Brasil ocupa a terceira posição,

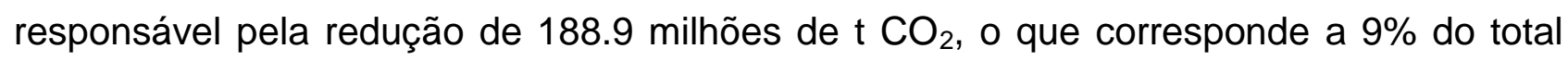
mundial, para o primeiro período de obtenção de créditos que podem ser de no máximo 10 anos para projetos de período fixo ou de 7 anos para projetos de período renovável

De acordo com estudo da Revista de Agronegócios da FGV são: 
[...] os fundos mundiais de mercado de carbono possuem U\$ 700 milhões para investir em projetos de geração de créditos de carbono, principalmente dentro do MDL. O Brasil pode ser responsável por algo em torno de 10\%do mercado de créditos de carbono gerados pelo MDL, sendo que a América Latina já negocia cerca de U\$210,5milhões, com 46 projetos no âmbito do MDL, que poderiam reduzir cerca de 55 milhões de toneladas equivalentes de $\mathrm{CO}_{2}$. O Brasil é o maior exportador potencial de créditos de carbono, segundo um estudo da Comissão Econômica para a América Latina (MERCADO, 2005).

Entre os principais projetos MDL no Brasil, de acordo com Cemano (2005, p.2), estão:

[...] co-geração de energia com biomassa; tratamento de Resíduos Sólidos Urbanos e aproveitamento de biogás em aterros sanitários; substituição de combustíveis e/ou aumento de eficiência energética em processos industriais; instalação de biodigestores para captação de metano em granjas de confinamento (particularmente suinocultura; implantação de pequenas centrais hidrelétricas (PCHs); e os projetos de reflorestamento.

Estes setores são os que mais atraem o interesse dos participantes de projetos. A predominância das atividades de projeto pode ser observada no gráfico a seguir:

\section{GRÁFICO - 1 - DISTRIBUIÇÃO DAS ATIVIDADES DE PROJETO NO BRASIL POR ESCOPO SETORIAL}

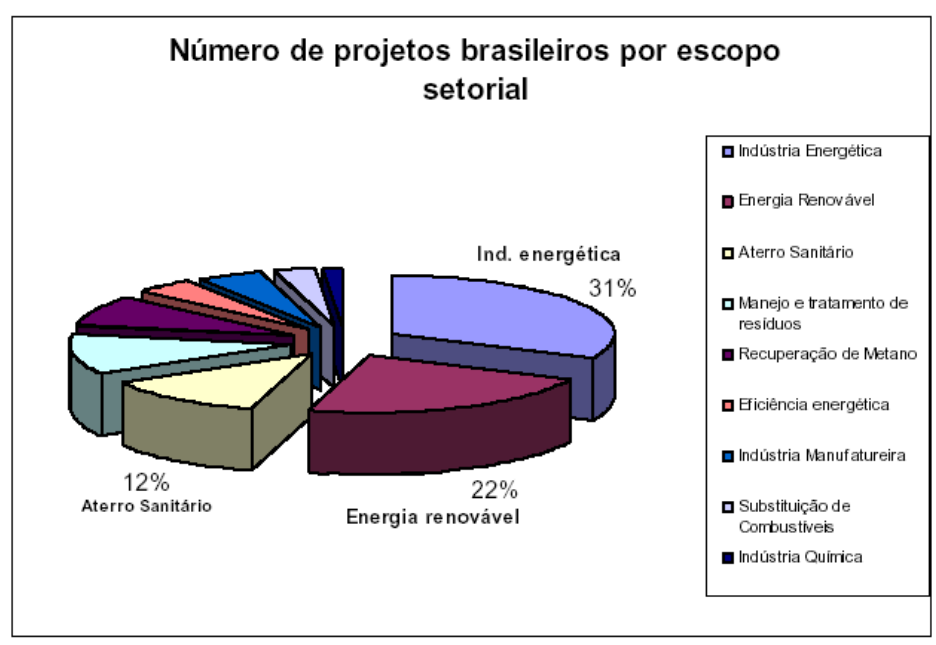

Fonte: Ministério da Ciência e Tecnologia ${ }^{5}$ (2006 apud Justi, 2007, p.8)

\footnotetext{
5 Ministério da Ciência e Tecnologia. Numero de projetos brasileiros por escopo setorial. 2006. Disponível em: <http://www.mct.gov.br/upd_blob/11677.pdf >. Acesso em: 17 dez. 200.
} 


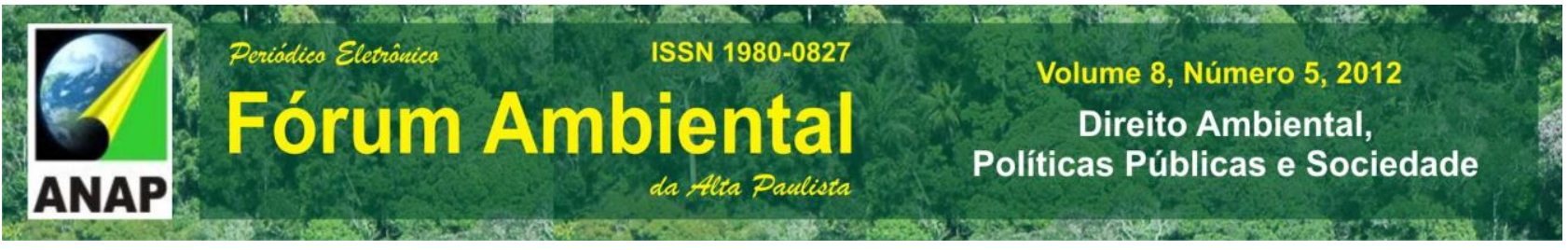

Novamente para Klabin (2000, p.41), “o Brasil encontra-se em uma situação ímpar, pelo grande território que ocupa em latitudes tropicais e semitropicais, para desenvolver reflorestamentos voltados para absorção de carbono." A potencialidade brasileira nos mercados de crédito de carbono dentro do MDL é devida, sobretudo, a sua vantagem competitiva no setor agropecuário, onde está concentrado o maior volume de projetos relacionado ao aproveitamento de resíduos para geração de energia (queima de bagaço de cana no setor sucro-alcooleiro e biodigestores), matriz energética limpa, com destaque para hidroelétricas e combustíveis renováveis e agroflorestais, onde a recuperação da vegetação original está associada à florestas de uso múltiplos através do plantio de espécies nativas e espécies de crescimento rápido, implicando na absorção de $\mathrm{CO}_{2}$ e na manutenção dos outros serviços ambientais das florestas.

Logo, o potencial de oportunidades para projetos de MDL no Brasil para energia, resíduos sólidos, eficiência energética e florestas está sintetizado na tabela a seguir.

\section{TABELA 2 - MATRIZ CONSOLIDADA DAS OPORTUNIDADES DE PROJETOS MDL - ENERGIA, RESIDUOS SÓLIDOS, EFICIÊNCIA ENERGÉTICA E FLORESTAS}

\begin{tabular}{|c|c|c|c|c|c|c|}
\hline $\begin{array}{c}\text { TIPOS DE } \\
\text { TRANSAÇÕES }\end{array}$ & $\begin{array}{c}\text { Geração } \\
\text { elétrica a } \\
\text { partir de } \\
\text { fontes } \\
\text { renováveis } \\
\text { de energia }\end{array}$ & $\begin{array}{l}\text { Resíduos } \\
\text { sólidos } \\
\text { urbanos }\end{array}$ & $\begin{array}{l}\text { Eficiência } \\
\text { energética }\end{array}$ & Florestas & $\begin{array}{c}\text { Combustíveis } \\
\text { líquidos } \\
\text { renováveis }\end{array}$ & TOTAL \\
\hline \multirow{2}{*}{$\begin{array}{l}\text { Potencial de } \\
\text { iniciativas em } \\
\text { andamento }\end{array}$} & $\begin{array}{c}1,75 \text { a } 4,210^{6} \\
\text { t CO } / \text { ano }\end{array}$ & $\begin{array}{l}2,310^{6} \mathrm{t} \\
\mathrm{CO}_{2} / \mathrm{ano}\end{array}$ & $\begin{array}{c}6,5 \text { a } 12,2 \\
10^{6} \mathrm{t} \\
\mathrm{CO}_{2} / \mathrm{ano}\end{array}$ & $\begin{array}{l}2,9210^{6} \mathrm{t} \\
\mathrm{CO}_{2} / \text { ano }\end{array}$ & - & $\begin{array}{c}13,5 \text { a } 21,6 \\
10^{6} \mathrm{t} \\
\mathrm{CO}_{2} / \text { ano }\end{array}$ \\
\hline & $\begin{array}{c}\text { US\$ 8,75 a } \\
21 \\
\text { milhões/ano }\end{array}$ & $\begin{array}{l}\text { US } \$ 11,4 \\
\text { milhões/ano }\end{array}$ & $\begin{array}{c}\text { US } \$ 33,1 \text { a } \\
\quad 61,2 \\
\text { milhões/ano }\end{array}$ & $\begin{array}{c}\text { US } \$ 5,4 \\
\text { milhões/ ano }\end{array}$ & - & $\begin{array}{c}\text { US\$ 58,6 a } \\
99,0 \\
\text { milhões/ano }\end{array}$ \\
\hline $\begin{array}{l}\text { Potencial de } \\
\text { iniciativas }\end{array}$ & $\begin{array}{c}10,0 \text { a } 19,6 \\
10^{6} \text { t } \mathrm{CO}_{2} \text { /ano }\end{array}$ & $\begin{array}{c}11,5 \text { a } 12,1 \\
10^{6} \mathrm{t} \\
\mathrm{CO}_{2} / \mathrm{ano}\end{array}$ & $\begin{array}{c}0,15410^{6} \mathrm{t} \\
\mathrm{CO}_{2} / \mathrm{ano}\end{array}$ & & $\begin{array}{c}5,5 \text { a } 6,210^{6} \\
\mathrm{CO}_{2} / \text { ano }\end{array}$ & $\begin{array}{c}24,2 \text { a } 38,1 \\
10^{6} t \\
\mathrm{CO}^{2} / \text { ano }\end{array}$ \\
\hline
\end{tabular}




\section{Periódica Eletrónica

\begin{tabular}{|c|c|c|c|c|c|c|}
\hline \\
\hline $\begin{array}{l}\text { tecnicamente } \\
\text { viáveis no } \\
\text { curto/médio } \\
\text { prazo }\end{array}$ & $\begin{array}{c}\text { US } \$ 49,9 \text { a } \\
\quad 98,1 \\
\text { milhões/ano }\end{array}$ & $\begin{array}{c}\text { US } \$ 57,7 \text { a } \\
\quad 60,1 \\
\text { milhões/ano }\end{array}$ & $\begin{array}{c}\text { US\$ 0,771 } \\
\text { milhões/ano }\end{array}$ & & $\begin{array}{c}\text { US } \$ 27,2 \text { a } 30,7 \\
\text { milhões/ano }\end{array}$ & $\begin{array}{l}\text { US\$ } 135,6 \text { a } \\
189,7 \\
\text { milhões/ano }\end{array}$ \\
\hline \multirow{2}{*}{$\begin{array}{c}\text { Potencial } \\
\text { teórico de } \\
\text { projetos de } \\
\text { florestamento e } \\
\text { reflorestamento }\end{array}$} & & & - & $\begin{array}{l}47,710^{6} \mathrm{t} \\
\mathrm{CO}_{2} / \mathrm{ano}\end{array}$ & & $\begin{array}{l}47,710^{6} \mathrm{t} \\
\mathrm{CO}_{2} / \mathrm{ano}\end{array}$ \\
\hline & - & - & - & $\begin{array}{c}\text { US } \$ 47,7 \text { a } \\
242 \\
\text { milhões/ano }\end{array}$ & & $\begin{array}{c}\text { US\$ } 47,7 \text { a } \\
242 \\
\text { milhões/ano }\end{array}$ \\
\hline \multirow{2}{*}{ TOTAL } & $\begin{array}{l}11,75 \text { a } 23,8 \\
10^{6} \mathrm{t} \mathrm{CO}_{2} \text { /ano }\end{array}$ & $\begin{array}{c}13,8 \text { a } 14,4 \\
10^{6} \mathrm{t} \\
\mathrm{CO}_{2} / \mathrm{ano}\end{array}$ & $\begin{array}{c}6,7 \text { a } 12,4 \\
10^{6} \mathrm{t} \\
\mathrm{CO}_{2} / \mathrm{ano}\end{array}$ & $\begin{array}{l}50,610^{6} \mathrm{t} \\
\mathrm{CO}_{2} / \mathrm{ano}\end{array}$ & $\begin{array}{c}5,5 \text { a } 6,210^{6} \mathrm{t} \\
\mathrm{CO}_{2} / \text { ano }\end{array}$ & $\begin{array}{l}88,3 \text { a } 107,4 \\
10^{6} \mathrm{CO}_{2} / \text { ano }\end{array}$ \\
\hline & $\begin{array}{c}\text { US\$ 58,7 a } \\
119,1 \\
\text { milhões/ano }\end{array}$ & $\begin{array}{c}\text { US\$ } 69,1 \text { a } \\
71,5 \\
\text { milhões/ano }\end{array}$ & $\begin{array}{c}\text { US\$ 33,9 a } \\
62,00 \\
\text { milhões/ano }\end{array}$ & $\begin{array}{c}\text { US\$ 53,1 a } \\
247,9 \\
\text { milhões/ano }\end{array}$ & $\begin{array}{c}\text { US\$ } 27,2 \text { a 30,7 } \\
\text { milhões/ano }\end{array}$ & $\begin{array}{c}\text { US\$2 } 241,9 \text { a } \\
531,2 \\
\text { milhões/ano }\end{array}$ \\
\hline
\end{tabular}

Fonte: Núcleo de Assuntos Estratégicos da Presidência da República ${ }^{6}$ (2005 apud Rezende, Dalmácio e Ribeiro, 2012, p. 112).

No entanto, para Moreira e Giometti (2008), para a materialização deste cenário, é preciso que o Protocolo de Kyoto se consolide como um acordo internacional com força legal, onde só será possível com a adesão dos EUA.

De acordo com Rezende, Dalmácio e Ribeiro (2012), para o período 2013-2017 (segundo período de compromisso de acordo com o Protocolo de Kyoto), as incertezas são maiores, o que dificulta a realização de projeções e de negócios ligados ao MDL.

Sendo assim, as principais incertezas para Bruno Filho (2010) são:

- Futuro Incerto: a indefinição sobre o pós 2012, em relação a um acordo climático global que substitua ou complemente o Protocolo de Kyoto, tornou-se um fator de incerteza no MDL;

\footnotetext{
${ }^{6}$ NÚCLEO DE ASSUNTOS ESTRATÉGICOS DA PRESIDÊNCIA DA REPÚBLICA. Processos estratégicos de longo prazo. Cadernos NAE, Brasília, v. 2, n. 4, p. 1-20, 2005.
} 
- Janela de Tempo: O tempo necessário para validar, registrar e emitir os RCEs de um projeto nas Nações Unidas leva geralmente de 18 a 24 meses, podendo até ser superior;

- Custo x Risco: o custo de transação do projeto de MDL pode ficar entre 150 mil a 200 mil dólares, o que representa um obstáculo para as micros, pequenas e médias empresas. Estruturar o projeto com recursos próprios e ao mesmo tempo correr os riscos inerentes tem gerado desistência;

- Complexidade do processo: as etapas de desenvolvimento e aprovação do projeto de Mecanismo de Desenvolvimento Limpo são complexas e passam por avaliações criteriosas e lentas. Além disso, questões relativas à interpretação de critérios como Adicionalidade, por exemplo, tem colocado à margem potenciais projetos.

\section{CONCLUSÃO}

O conceito de sustentabilidade pressupõe em linhas gerais o desenvolvimento econômico aliado ao bem estar social e a preservação do meio ambiente. Sendo assim, o mercado de créditos de carbono através do Mecanismo de Desenvolvimento Limpo, criado na $3^{\circ}$ Conferencia das Partes em Kyoto, no Japão, permite que países desenvolvidos comprem reduções de emissões de países em desenvolvimento cujas reduções são resultantes de iniciativas implementadas com o objetivo de diminuir a emissão de $\mathrm{CO}_{2}$ e outros GEE.

O MDL é a oportunidade para a promoção do desenvolvimento sustentável em escala global, pois contempla o desenvolvimento das atividades econômicas e financeiras nos países envolvidos no Mecanismo de Desenvolvimento Limpo. Através da comercialização de créditos de carbono, possibilita a geração de emprego, renda e qualidade de vida através de investimento em projetos e tecnologias limpas nos países subdesenvolvidos e emergentes. Além disso, permite a preservação do meio ambiente, por meio da mitigação de GEE e projetos de florestamento e reflorestamento.

Em um cenário onde o efeito estufa pode trazer mudanças irreversíveis na dinâmica climática global como: aumento do nível dos oceanos, aumento da incidência de doenças transmissíveis, alteração no regime pluvial, intensificação de fenômenos 
climáticos extremos, desertificação e perda de áreas agricultáveis, problemas relacionados ao abastecimento de água doce e aumento de fluxos migratórios. Além disso, com a atual crise econômica nos mercados desenvolvidos e seus desdobramentos nos países subdesenvolvidos e as consequências sociais da mesma em escala mundial: queda na renda, desemprego, aumento da pobreza, aumento das desigualdades sociais, aumento do número de conflitos e da violência em geral, somente vem corroborar a importância e necessidade de ampliação do MDL.

Porém com a negativa dos Estados Unidos em ratificar o Protocolo de Kyoto , a expiração do mesmo ao final de 2012 e a complexidade, os custos e os riscos para o desenvolvimento e aprovação de projetos de Mecanismo de Desenvolvimento Limpo, junto as Nações Unidas, ameaçam o desenvolvimento deste mercado de credito de carbono.

Logo, neste cenário sistêmico, é preciso que o Brasil, um dos países mais beneficiados pelo MDL, (com projetos nos setores de energia, resíduos sólidos, eficiência energética e florestas com expectativas de ganho de cerca de US\$ 241,9 a 531,2 milhões/ano), através de seu corpo diplomático, defenda nas reuniões das Conferências das Partes um segundo período de compromisso do Protocolo de Kyoto (2013 - 2017). Outrossim, articulado com outras nações ações como: a simplificação do desenvolvimento e a aprovação de projetos MDL junto as Nações Unidas e negociação juntamente com o governo americano para ratificação do protocolo de Kyoto.

Somente através destas ações, o Mecanismo de Desenvolvimento Limpo pode se consolidar como um mercado de crédito de carbono capaz de promover em longo prazo o desenvolvimento sustentável (econômico, social e preservação ambiental) tanto para os países desenvolvidos, quanto para os países emergentes e subdesenvolvidos.

\section{REFERENCIAS}

ANDRADE, Maria Margarida. Introdução à metodologia do trabalho científico: elaboração de trabalhos na graduação. 4 ed. São Paulo: Atlas, 1998. 
ARRHENIUS, Svante. On the Influence of Carbonic Acid in the Air upon the Temperature of the Ground.Royal Swedish Academy of Science. Philosophical Magazine, London, $n^{\circ}$ 5, p. 237-276, 1896.

ASSIS, Maria Cristina. Metodologia do Trabalho Cientifico. João Pessoa: UFPB. 2009, 48 p. Disponível em: < Disponível em: < http://portal.virtual.ufpb.br/biblioteca virtual/files/pub_1291081139.pdf >. Acesso em: 01 jul. 2012.

BEN, Fernando; TONELLO, Keli Arisi. Analise do Reconhecimento de Credito de Carbono. In: XI CONVENÇÃO DE CONTABILIDADE, 2007, Rio Grande do Sul. Artigo Completo... Rio Grande do Sul: UCS, 2007. Disponível em: $<$ http://www.brasil.gov.br/cop17/panorama/a-convencao-quadro-das-nacoes-unidassobre-mudanca-do-clima>. Acesso em: 01 jul. 2012.

BM\&F BOVESPA. Levantamento de Oportunidades Concretas de Projetos de Baixo Carbono no Brasil. Disponível em: <http://www.bmfbovespa.com.br/pt$\mathrm{br} /$ mercados/download/Levantamento-de-Oportunidades-Concretas-de-Projetos-de-BaixoCarbono-no-Brasil.pdf.>. Acesso em: 01 jul. 2012.

BRASIL.Convenção Quadro das Nações Unidas sobre Mudanças do Clima.

Disponível em: <http://www.brasil.gov.br/cop17/panorama/a-convencao-quadro-dasnacoes-unidas-sobre-mudanca-do-clima>. Acesso em: 01 jul. 2012.

BRASIL. Ministério da Ciência e da Tecnologia. Protocolo de Quioto. Brasília, 2002. Disponível em: <http://www.mct.gov.br>. Acesso em: 01 jul. 2012.

BRASIL. Presidência da República. Núcleo de Assuntos Estratégicos.Oportunidades de negócios em segmentos produtivos nacionais. In: [s.n.], 2005b. v. 2 (Cadernos NAE, 04). p. 115-303. .Mudança do clima. Brasília:

BRUNO FILHO, Laércio. Oportunidades de negócio com créditos de carbono no Brasil. Revista HSM. Disponível em:

<file:///E:/Credito\%20de\%20carbono/Oportunidades\%20de\%20neg\%C3\%B3cio\%20com\% 20cr\%C3\%A9ditos\%20de\%20carbono\%20no\%20Brasil\%20\%20\%20Portal\%20HSM.htm> Acesso em: 01 jul. 2012.

CEMANO. Mariano. Colini. O Mercado de credito de carbono e as oportunidades para o agronegócio brasileiro. Disponível em:<www.cepea.esalq.usp.br/economiaambiental> Acesso em: 01 jul. 2012.

CONEJERO, Marco. Antonio. Marketing de créditos de carbono: um estudo exploratório. 2006. Dissertação (Mestrado em Administração) - Faculdade de Economia, Administração e Contabilidade de Ribeirão Preto, Universidade de São Paulo, Ribeirão Preto, 2006. 
CONTI. Jose Bueno. Considerações sobre as mudanças climáticas globais. Revista do Departamento de Geografia, São Paulo, n. 16, p. 70-75, 2005.

FERRARESI DE ARAUJO, Geraldo Jose; CARVALHO, Cesar Machado. A Agenda 21 e a Elaboração de Políticas Públicas para a Sustentabilidade Urbana. Periódico Eletrônico Fórum Ambiental da Alta Paulista, Tupã, v. 07, n. 04, p. 685-699, 2011. Disponível em: < http://www.amigosdanatureza.org.br/publicacoes/index.php/forum/article/view/144/145>. Acesso em: 01 jul. 2012.

GIL, Antonio Carlos. Métodos e Técnicas de Pesquisa Social. 5. ed. São Paulo: Atlas,2006.

JUSTI, Edrilene Barbosa Lima. Mecanismo de Desenvolvimento Limpo. Disponível em: <http:www.selvaflorestal.com/download?download=19>. Acesso em de 01 jul. 2012.

KLABIN, Israel. O mecanismo de Desenvolvimento Limpo e as Oportunidades Brasileiras. Parcerias Estratégicas, Brasília, n 9, p. 35 - 53, 2000.

MERCADO de carbono na ponta do lápis. Agroanalysis: Revista de Agronegócios da FGV, São Paulo, v. 25, n. 1, p. 37-39, jan. 2005.

MINISTÉRIO DA CIÊNCIA E DA TECNOLOGIA. Convenção-Quadro das Nações Unidas sobre Mudança do Clima. Disponível em:

<http://acessibilidade.mct.gov.br/index.php/content/view/35589.html.>. Acesso em: 01 jul. 2012.

MOREIRA, Helena Margarido; GIOMETTI, Analúcia Bueno Reis. Protocolo de Quioto e as possibilidades de inserção do Brasil no Mecanismo de Desenvolvimento Limpo por meio de projetos em energia limpa. Contexto Internacional. Rio de Janeiro, v. 30, n. 1, 2008.Disponível em:

$<$ http://www.scielo.br/scielo.php?script=sci_arttext\&pid=S010285292008000100001\&lng= en\&nrm=iso >. Acesso em: 01 jul. 2012.

NISHI, Marcos Hiroshi et al. Influencia dos créditos de carbono na viabilidade financeira de três projetos florestais. Revista Arvore, Viçosa, v.29, n.2, p.263-270, 2005.

REZENDE, Amaury Jose; DALMACIO, Flavia Zoboli; RIBEIRO, Maisa, Souza. A Potencialidade dos Créditos de Carbono na Geração de Lucro Econômico Sustentável da Atividade de Reflorestamento. Organizações Rurais e Agroindustriais, Lavras, v. 14, n. 1, p. 108-126, 2012.

ROCHA, Marcelo Theoto. Aquecimento global e o mercado de carbono: uma aplicação do modelo CERT. 2003. Tese (Doutorado em Economia Aplicada) - Escola Superior de Agricultura Luiz de Queiroz, Universidade de São Paulo, Piracicaba, 2003. Disponível em: http:www.teses.usp.brtesesdisponiveis1111132tde-13052003-163913. Acesso em: 01 jul. 2012. 
SCARPINELLA, Gustavo Almeida. Reflorestamento no Brasil e o Protocolo de Quioto. 2002. Dissertação (Mestrado em Energia) - Instituto de Eletrotécnica e Energia, Universidade de São Paulo, São Paulo, 2002.

SOUZA, Clóvis; MILER, Daniel. O Protocolo de Quioto do Mecanismo de Desenvolvimento Limpo (MDL) às Reduções Certificadas de Emissões (RCEs), sua natureza jurídica e a regulação do mercado de valores mobiliários, no contexto estatal pós-moderno. COMISSÃO DE VALORES MOBILIÀRIOS - CVM-. São Paulo, 2003

SOUZA, Helcio. O Grupo Banco Mundial e as estratégias de gestão ambiental global para o Brasil. In: BARROS, Flávia. (org.) et alli. As Estratégias dos Bancos Multilaterais para o Brasil. Brasília: Rede Brasil, 2001.

UNITED NATIONS FRAMEWORK CONVENTION ON CLIMATECHANGE. Text of the Convention. Disponível em: <

http://unfccc.int/key_documents/the_convention/items/2853.php .>. Acesso em: 01 jul. 2012.

YU, Chang Man. Seqüestro Florestal de Carbono no Brasil. São Paulo: Annablume, 2004.

ZILBER, Silvia Novaes; KOGA, Eduardo. Mercado de Creditos de Carbono no Brasil e o Papel dos Agentes Intermediários: Desafios e Oportunidades. Organizações Rurais e Agroindustriais, Lavras, v. 13, n. 1, p. 139-153, 2011 